\section{Persistent Arctic ozone layer}

SIR-The Arctic ozone layer has been studied since 1935 from the Norwegian station in Troms $\varnothing\left(70^{\circ} \mathrm{N}\right)$. Long series of observations are also available for the stations in Oslo $\left(60^{\circ} \mathrm{N}\right)$ and Spitsberggen $\left(79^{\circ} \mathrm{N}\right)$. The Oslo station, where the measurements are not hampered by the

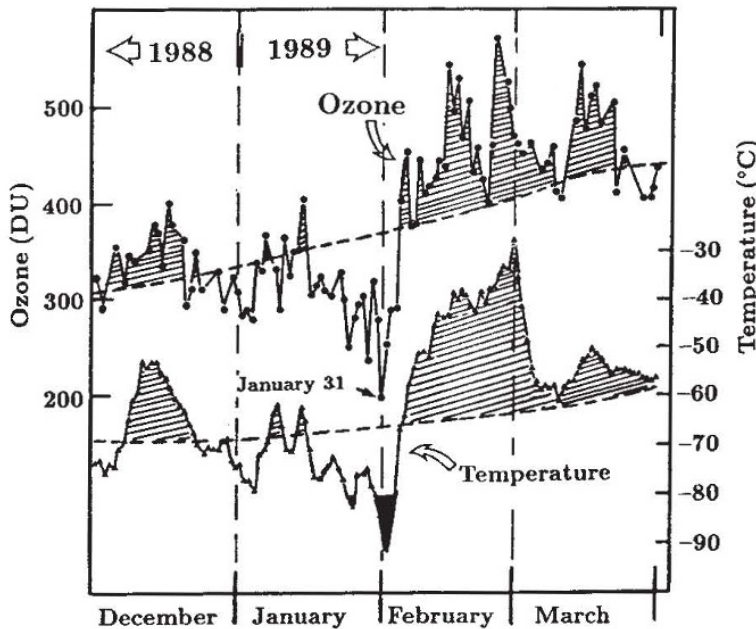

FIG. 1 Daily measurements of ozone (in DU) in Oslo and the 30-hPa ( 23-km altitude) temperature (ref. 3) for the position $60^{\circ} \mathrm{N}, 10^{\circ} \mathrm{E}$ (slightly west of Oslo) during the winter 1988-1989. The dashed lines are the average values. Periods above average are hatched. The shaded area indicates that the temperature was below $-80^{\circ} \mathrm{C}$ in the period with the large ozone depletion.

polar night, seems to be representative of the northern region.

Long-term measurements are needed for trend analyses, whereas the daily measurements give information about episodes with unusual ozone values. The data from long-term ozone measurements reveal periods of several years with a negative trend and other periods with a positive trend. The combined results up to 1989 give no evidence for a long-term negative trend of the Arctic ozone layer.

During the last days of January 1989 the ground-based Norwegian stations, as well as Nimbus 7, observed a 'mini-hole' in the ozone layer, centred over Scandinavia. On 31 January ( Fig. 1), an ozone value of only 200 DU (dobson units) about $45 \%$ below normal, was observed by the Oslo station. The depletion lasted for a few days, followed by a rapid increase and record high values early in February. According to satellite data and $100-\mathrm{hPa}(\sim$ $16-\mathrm{km}$ altitude) temperature contours, the 'mini-hole' was apparently filled with ozone-rich air from Canada and Alaska.

The ozone-depletion episode over Scandinavia was probably of meteorological origin, although we cannot exclude a small contribution due to heterogeneous chlorine chemistry involving chlorofluorocarbons (CFCs). The conditions for this type of ozone destruction include both low stratospheric temperatures (below $\sim-80^{\circ}$ C) with the formation of polar stratospheric clouds (PSCs) as well as sunlight.
Figure 1 shows that the $30-\mathrm{hPa}(\sim 23-\mathrm{km}$ altitude) temperature was sufficiently low wer days in the period during which we observed the mini-hole (shaded area), and at this latitude there is sunlight for a few hours every day. Based on balloon experiments (Kiruna, Sweden) in January 1989, Hofmann et al. ${ }^{1}$ suggested a small ozone destruction due to a combination of PSC formation and sunlight. The Oslo data do not conflict with this.

The ozone values observed at our stations were above average from early February 1989 (Figs 1, 2). Thus, the spring value (average of all measurements in the three months February, March and April) for Oslo was $6.5 \%$ above average and in Troms $\emptyset$ $10.5 \%$ above average (the highest value in $\sim 45$ years).

The ozone measurements from the Norwegian stations during the first four months of 1989 exhibit periods with both record low and high values. For trend analyses, it is therefore necessary to use the average value for a well defined time interval such as a month, a season or a year. In Fig. 2 the spring values for Troms $\varnothing$ (back to 1936) and Oslo are given. In Fig. 3 the summer values (average of the measurements in May, June, July and August) and the winter values (average of December, January, February and March) for Oslo (1978-1989) are presented together with Bojkov's ${ }^{2}$ results for 12 ozone stations north of $59^{\circ} \mathrm{N}$ for

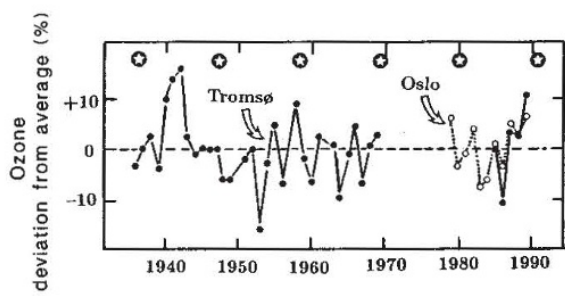

FIG. 2 Spring values (average of measurements in February, March and April corresponding to August, September and October in Antarctica) of ozone for Troms $\emptyset$ (filled circles) and Oslo (open circles). The data are given as per cent deviation from the average value, which for Oslo is $415 \mathrm{DU}$. For Tromsø we have a long period with no measurements. The stars indicate sunspot maxima. The Oslo data may indicate a correlation with the sunspot activity.

the period 1957-1986 The following conclusions can be drawn from the results presented in the two figures: (1) the ozone concentrations through the summer exhibit a smaller annual variation than both the winter values and the spring values; (2) the measurements for Oslo are in excellent agreement with the data ${ }^{2}$ for 12 different stations for the period in which they overlap (1978-1986). This observation indicates that the Oslo station is representative for the Arctic; (3) the data for

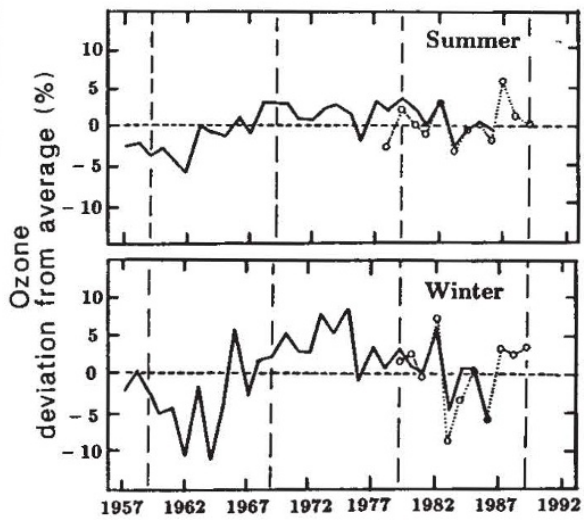

FIG. 3 Ozone data for Oslo for the period 1978 to 1989 and Bojkov's data ${ }^{2}$ for 12 stations north of $59^{\circ} \mathrm{N}$ for the period 1957 to 1986 . Summer data are the average of measurements in May, June, July and August and winter data the average of measurements in December, January, February and March. The results are given as per cent deviation from the average value which for Oslo is $368 \mathrm{DU}$ (summer) and $373 \mathrm{DU}$ (winter). The vertical lines indicate ten-year periods.

Oslo and Troms $\varnothing$ show that the ozone layer over Scandinavia has been above normal (or average) during the past three years. Because of the good correlations with the data from other stations this conclusion may be valid for the whole Arctic region; (4) the figures show the importance of defining the starting point and endpoint when describing trends. The data indicate a positive trend for ozone (in all seasons) in the period 1983-1989 (the past six years). On the other hand, no particular trend can be claimed for the past ten years. The 'winter data' in Fig. 3 indicate a small negative trend over the past 20 years and a similar, but positive, trend for the past 30 years; (5) These data indicate that anthropogenic gases such as CFCs have, up to the summer of 1989 , had a negligible influence on the Arctic ozone layer. The general balance between formation and destruction of ozone has not changed, at least not to an extent that is apparent in the long-term observations. Whether heterogeneous chlorine chemistry contributes to transient ozone depletions such as the mini-hole observed over Scandinavia in the last days of January 1989 is not yet established, but the possibility should be considered.

SøREN H. H. LARSEN THORMOD HENRIKSEN

Institute of Physics,

University of Oslo,

Blindern, 0316 Oslo 3, Norway

1. Hofman, D. J. et al. Nature 340, 117-121 (1989)

2. Bojkov, R. D. Met. atmos. Phys. 38, 117-127 (1988).

3. Naujokat, B., Labitzke, K., Lenshow, R., Petzoldt, K. \& Wohlfart, R. C. Beilage zur Berliner Wetterkarte SO 12 (1989). 